\title{
In-Situ Biofloc Affects the Core Prokaryotes Community Composition in Gut and Enhances Growth of Nile Tilapia (Oreochromis niloticus)
}

\author{
Yale Deng ${ }^{1} \cdot$ Klaudyna Borewicz $^{2,3} \cdot$ Joost van Loo ${ }^{1} \cdot$ Marko Zabala Olabarrieta $^{2} \cdot$ Fotini Kokou $^{1} \cdot$ Detmer Sipkema $^{2}$. \\ Marc C. J. Verdegem ${ }^{1}$
}

Received: 12 July 2021 / Accepted: 20 September 2021 / Published online: 5 October 2021

(c) The Author(s) 2021

\begin{abstract}
Biofloc technology is commonly applied in intensive tilapia (Oreochromis niloticus) culture to maintain water quality, supply the fish with extra protein, and improve fish growth. However, the effect of dietary supplementation of processed biofloc on the gut prokaryotic (bacteria and archaea) community composition of tilapia is not well understood. In this study one recirculating aquaculture system was used to test how biofloc, including in-situ biofloc, dietary supplementation of ex-situ live or dead biofloc, influence fish gut prokaryotic community composition and growth performance in comparison to a biofloc-free control treatment. A core gut prokaryotic community was identified among all treatments by analyzing the temporal variations in gut prokaryotes. In-situ produced biofloc significantly increased the prokaryotic diversity in the gut by reducing the relative abundance of dominant Cetobacterium and increasing the relative abundance of potentially beneficial bacteria. The in-situ biofloc delivered a unique prokaryotic community in fish gut, while dietary supplementation of tilapias with $5 \%$ and $10 \%$ processed biofloc (live or dead) only changed the relative abundance of minor prokaryotic taxa outside the gut core microbiota. The modulatory effect of in-situ biofloc on tilapia gut microbiota was associated with the distinct microbial community in the biofloc water and undisturbed biofloc. The growth-promoting effect on tilapia was only detected in the in-situ biofloc treatment, while dietary supplementation of processed biofloc had no effect on fish growth performance as compared to the control treatment.
\end{abstract}

Keywords Biofloc system $\cdot$ Ex-situ biofloc $\cdot$ Growth performance $\cdot$ Microbial community $\cdot$ Gut microbiota

\section{Introduction}

Biofloc is an aggregation of microorganisms-including bacteria, microalgae, fungi and zooplankton-and other organic particles suspended in the water column [1]. In aquaculture, the formation of biofloc is stimulated by increasing the organic carbon input and aerating the culture tank, resulting in the production of microbial biomass that could serve as natural food [2]. The ability to immobilize inorganic nitrogen waste into microbial biomass makes

Marc C. J. Verdegem

marc.verdegem@wur.nl

1 Aquaculture and Fisheries Group, Wageningen University and Research, Wageningen, The Netherlands

2 Laboratory of Microbiology, Wageningen University and Research, Wageningen, The Netherlands

3 Trouw Nutrition R\&D, 3811 MH Amersfoort, The Netherlands biofloc technology a sustainable method to improve water quality and to increase the nutrient recovery from fish feed into harvested biomass [3]. For instance, the herbivorousomnivorous Nile tilapia (Oreochromis niloticus) is known to eat biofloc [4], which results in a better growth than in recirculating aquaculture systems (RAS) without exhibiting adverse welfare effects [5]. Moreover, Nile tilapia grown in biofloc systems showed higher digestive enzyme activities, lower susceptibility to pathogens and a stronger immune response than in other culture systems [6, 7].

The growth-promoting effect of biofloc could be attributed to its nutritional value. Bacteria played an important role in the aquatic food web, for instance as a direct food source for aquaculture organisms, as an ingredient in formulated diets and the use of bacteria species as probiotics [8]. Biofloc harvested from Nile tilapia culture tanks had a similar or better proximate composition than the formulated feed fed to the system, with an amino acid composition meeting the nutritional requirement of tilapia $[5,9]$. 
It has been reported that biofloc provide extra essential nutrients including proteins, lipids, essential fatty acids, minerals, vitamins, carotenoids and exogenous digestive enzymes that may improve the nutritional status of the fish and shrimp [10-12]. The in-situ biofloc produced in a tilapia culture system can be harvested, dried and used to replace fish meal in formulated shrimp feed (i.e. ex-situ biofloc), resulting in faster growth than the biofloc-free control diet $[13,14]$. Therefore, biofloc is a valuable feed additive that contributes to the re-use of waste nutrients for sustainable aquaculture. However, the dietary role of biofloc in the growth performance of culture species needs further investigation.

Recently, biofloc has been applied as a strategy for disease management due to its probiotic effect on animal health [15]. The beneficial bacteria and its bioactive compounds, such as polyhydroxy butyrate, present in biofloc could increase the immune response and protect shrimp or fish against bacterial infections $[6,16,17]$. The high concentration of organic matter and its associated load of microorganisms in a biofloc system can influence the gut microbiota due to the constant grazing of the culture species on biofloc. Nile tilapia larvae cultured in biofloc system showed different gut microbiota composition with tilapia grown in RAS [18]. Biofloc produced with different carbon sources or feed ratios resulted in different microbial community composition in the gut of tilapia $[9,19,20]$. Gut microbiota played an important role in nutrient digestibility and immune response, thus influencing the growth and health of aquatic animals [21-23]. However, how in-situ biofloc influence the gut microbiota composition in Nile tilapia and whether the dietary supplementation of ex-situ biofloc can change the gut microbiota and growth of tilapia remains unknown.

In aquaculture, a probiotic was defined as "a live microbial adjunct which has a beneficial effect on the host by modifying the host-associated or ambient microbial community, by ensuring improved use of the feed or enhancing its nutritional value, by enhancing the host response towards disease" [24]. Therefore, to distinguish between the nutritional value and probiotic effect of biofloc on fish, in-situ biofloc were harvested and incorporated into fish feed as live biofloc or $\gamma$-radiated dead biofloc. Giatsis et al. [25] showed large variations existing in the water and fish gut microbial community of replicate culture systems. Therefore, in this study one recirculating system was used for all the treatments to minimize system effects on water microbial community composition in the rearing tanks. In the recirculating system, live biofloc feed (LF), dead biofloc feed (DF) and biofloc-free feed (Ctrl) were fed to tilapia. In addition, the biofloc-free feed was also fed to tilapia swimming in tanks with in-situ biofloc (LW). The aim of this study was to test how in-situ biofloc (LW) and dietary supplementation of ex-situ biofloc (DF and LF) influence the gut microbiota development and the growth performance of tilapia as compared with the Ctrl treatment.

\section{Materials and Methods}

\section{Experimental Setup and Animal Accommodation}

This experiment was carried out between October, 2015 and November, 2015. Six treatments were randomly divided over eighteen $30-\mathrm{L}$ tanks (3 replicates per treatment) that were part of one recirculating aquaculture system (Fig. 1). The live water $(\mathrm{LW})$ treatment received biofloc water from a biofloc production system in which six tilapia fish tanks was placed for biofloc production. Biofloc water was also collected daily from a swirl separator (Fig. 1, swirl separator top-left) and passed through a paper filter. The collected biofloc on filters was semi-dried at room temperature in the lab until 5\% moisture. The unprocessed biofloc contained on a dry matter basis $(\mathrm{g} / \mathrm{kg}) 513$ crude protein, 317 carbohydrates and 110 ash. In this study, the control diet was prepared by Research Diet Services BV in the Netherlands, using mainly wheat, maize, fish meal and soya bean meal as raw ingredients. The feed contained on a dry matter basis $36.2 \%$ crude protein, $6.2 \%$ crude fat, $7.2 \%$ crude ash, $23.9 \%$ starch and $1.05 \%$ total phosphorous. The control diet was crumbled and mixed with the semi-dried biofloc, on a dry matter basis at a dose of 5 or $10 \%$ of the control feed amount. Half of the feed obtained in this way is referred to as live biofloc feed (LF5 at 5\% addition and LF10 at 10\% addition). The other half of the feed was $\gamma$-radiated (Synergy Health, Ede, the Netherlands) at the dose of 8000 Gy (Gy) to kill microbiota, which is referred as dead biofloc feed (DF5 at $5 \%$ addition and DF10 at 10\% addition). Both LW and Ctrl treatments received control diet which was also crumbled into a dough and processed into pellets, following the same process as for the LF and DF treatments. The effluent of LW tanks was led to a swirl separator (Fig. 1, swirl separator bottom-left) to return the biofloc back to production system and the overflow was passed through an ozone treatment unit and a UV-lamp to oxidize and inactive the bacteria remaining in biofloc water. A sump (Fig. 1, bottom-right) was placed to receive the effluents from all the treatment tanks and maintain the water temperature at $28{ }^{\circ} \mathrm{C}$ with a heater. From the sump, the water was pumped to a settling tank for solids removal and subsequently over a trickling biofilter for ammonium removal before returning to each treatment tank.

In each tank, 33 Nile tilapia (Til-Aqua, Velden, the Netherlands) were stocked at the start of the experiment with an average body weight of $0.58 \mathrm{~g}$. The fish were fed using a belt feeder from $10 \mathrm{a} . \mathrm{m}$. over a period of $10 \mathrm{~h}$ daily at the ratio of $16 \mathrm{~g}$ per kg metabolic weight $\left(16 \mathrm{~g} \mathrm{~kg}^{-0.8} \mathrm{day}^{-1}\right)$. The diet applied in this experiment was a commercial diet that was 


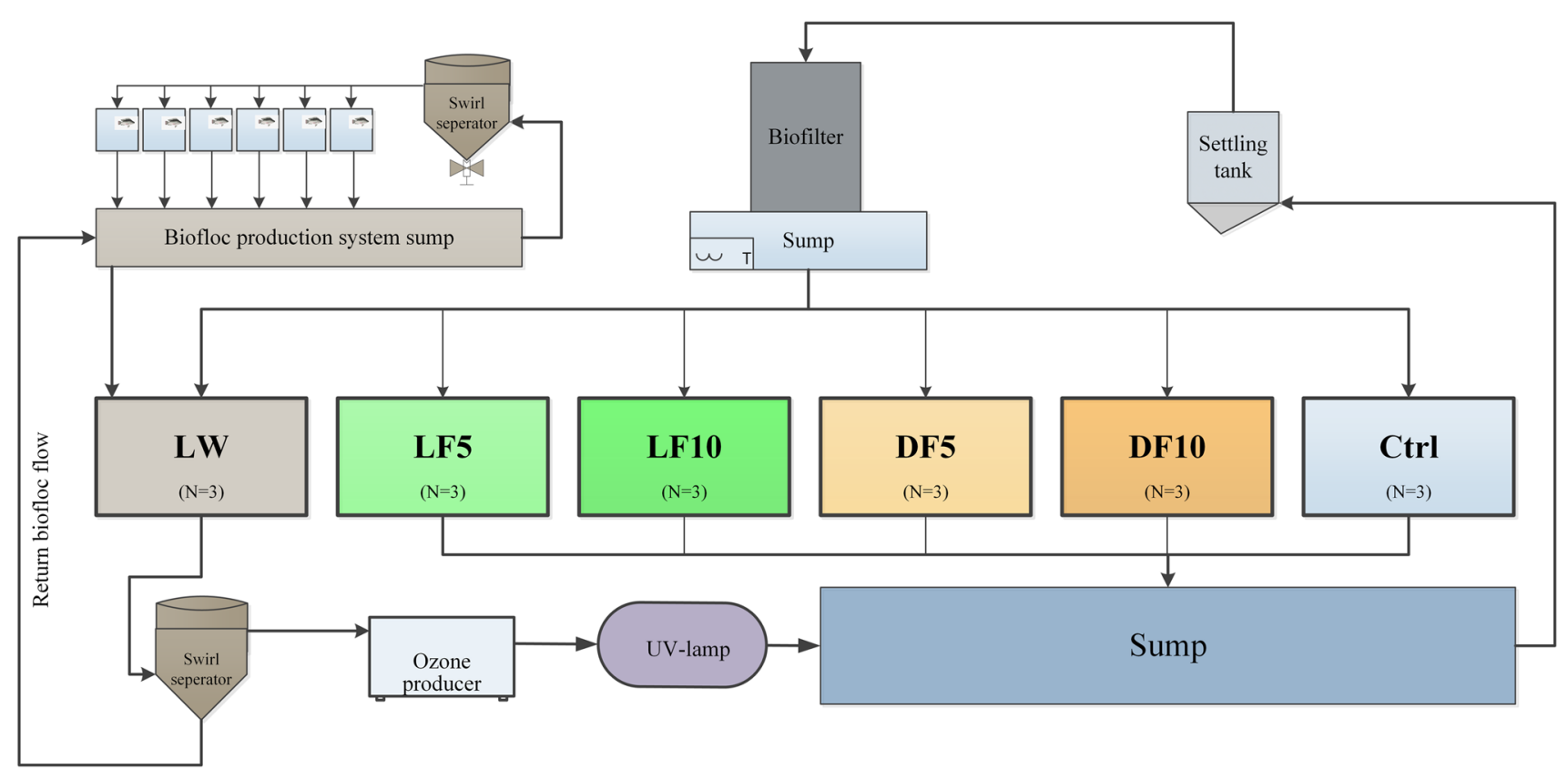

Fig. 1 Experimental setup and treatment groups. Experimental fish were stocked in six treatment groups with each group containing three replicates $(N=3)$. LW treatment received in-situ biofloc water originating from a biofloc production system and was fed with control

sterilized by $\gamma$-radiation with a dose of 8000 Gy before use in all treatments. All experimental treatments were randomly assigned to the tanks to exclude the potential influence of location-associated factors.

\section{Samples Collection from Gut, Water, Flocs and Feed}

Fish gut, tank water, biofloc and feed samples were collected on days 0,26 and 49 according to a previously described protocol [25]. Ten fish were sampled on day 0 for the analysis of the initial gut microbiota, and 5 fish per tank were randomly sampled at later timepoints for the intestinal microbiota analysis on days 26 and 49. Fish were euthanized with $0.6 \mathrm{~g} \mathrm{~L}^{-1}$ Tricaine Methanesulfonate (TMS, Crescent Research Chemicals, Phoenix, Arizona, USA), then rinsed with $70 \%$ ethanol and sterile water before dissecting out the gut. Moreover, $100 \mathrm{~mL}$ of water from each tank was collected in three replicates and filtered through 0.45 and $0.22 \mu \mathrm{m}$ membrane filters (Millipore-Isopore), the two filters were pooled together for DNA extraction. In addition, $100 \mathrm{~mL}$ water was also sampled in five replicates from the biofloc production system sump and filtered over a paper filter to collect biofloc. Finally, $2 \mathrm{~g}$ samples of feed prepared for LF5, LF10, DF5, DF10 and LW/Ctrl (control diet) were collected in three replicates. All samples were flash frozen in liquid nitrogen and stored individually at $-80^{\circ} \mathrm{C}$ for the prokaryotic community composition analysis. Moreover, the average individual weights of fish on days 0,26 and 49 was diet. LF and DF treatment received a diet containing the same feed ingredients as control diet, plus ex-situ live biofloc or dead biofloc, respectively, at 5\% (LF5, DF5) or 10\% (LF10, DF10) on dry weight basis. Ctrl treatment received control diet without biofloc

measured to evaluate the fish growth performance during the experiment.

\section{Genomic DNA Extraction and 165 rRNA Gene Sequencing}

DNA extraction from fish gut samples was conducted using the DNeasy Blood \& Tissue Kit (Qiagen, Venlo, Netherlands), whereas the FastDNA SPIN kit for soil (MP Biomedicals, Ohio, USA) was used for water, feed and biofloc samples. The V4 region of 16S rRNA gene was amplified using uniquely barcoded primers 515F (5'-GTGCCA GC[AC]GCCGCGGTAA-3') and 806R (5'-GGACTA C[ACT][ACG]GGGT[AT]TCTAAT-3') [26]. The amplicon libraries were HiSeq sequenced (GATC-Biotech, Konstanz, Germany) and sequencing data were processed and analyzed with NG-Tax using default parameters [27]. In brief, libraries were filtered to contain only read pairs with perfectly matching barcodes that were subsequently used to separate reads by sample. Unique sequences (operational taxonomic units, OTUs) occurring above a minimum $0.1 \%$ relative abundance threshold per sample were picked, and subjected to non-reference-based chimera checking, where the parent sequence needed to be more abundant by a 0.5 ratio than the chimeric sequence. Taxonomy was assigned using the SILVA_111_SSU reference database [28]. Samples with a low number of sequencing reads $(<1500)$ were removed from analysis. 


\section{Data Analysis}

The fish growth performance during the experiment was assessed by weight gain (WG), and metabolic growth rate (MGR), which were calculated as previously described [29]: $\mathrm{WG}=W_{f} \quad-\quad W_{i}, \quad \mathrm{GBW}=e^{\left(\ln \mathrm{W}_{\mathrm{f}}+\ln W_{i}\right) / 2}$, $\mathrm{MGR}=\mathrm{WG} *\left(\frac{\mathrm{GBW}}{1000}\right)^{-0.8} / t$, where $W_{f}(\mathrm{~g})$ and $W_{i}(g)$ are the final and initial average body weight, WG $(\mathrm{g})$ is the weight gain, GBW $(\mathrm{g})$ is the geometric mean body weight, and MGR $\left(\mathrm{g} \mathrm{kg}^{-0.8} \mathrm{day}^{-1}\right)$ is the metabolic growth rate, $t$ is the number of days. The growth performance was expressed in metabolic body weight to minimize the differences in maintenance levels between smaller and larger fish. The growth performance was compared among the six treatments by repeated measures ANOVA to analyze the interaction between treatments and growth for the periods of $\mathrm{d} 0-\mathrm{d} 26$ and d27-d44 using IBM SPSS statistics software.

A total of 391 experimental samples were sequenced, with a combined number of $65,383,991$ sequencing reads (range 4 to 740,934 reads, median $=138,760$ ). Four samples, including one Ctrl, two DF water and one LW feed, were removed from analyses due to the low number of reads $(<1500)$. Series of rarefactions were performed prior to alpha diversity analyses at cut offs between 1500 and 10,000 reads. The cutoff value was then chosen to provide maximum coverage while allowing most samples to be retained for the analyses. As a result, data were rarified at 2500 reads and four gut samples were removed because their read numbers were below this threshold. Alpha diversity indices, including Shannon, Chao 1, and Phylogenetic Diversity (PD) Whole Tree, for each gut sample were calculated on genus level data using QIIME [30]. Resulting diversity scores were compared between different treatment groups using nonparametric $t$-test with Monte Carlo permutations $(n=999)$. Statistical differences in relative abundance (RA) of genus level taxa and phylotypes (OTUs) between treatments were assessed with Kruskal-Wallis test using QIIME. The UniFrac distance between all gut samples based on weighted data were compared using analysis of similarity (ANOSIM) test in QIIME. Principal coordinate analysis (PCoA) and redundancy analysis (RDA) were calculated in Canoco5 using the log transformed genus level relative abundances data. Statistical between treatments was assessed in Canoco5 under the full model using the Monte Carlo permutation test with 499 random permutations [31].

\section{Results}

\section{Fish Growth Performance}

At the start on $\mathrm{d} 0$, fish from each tank had a similar average body weight $(0.58 \mathrm{~g})$ for all treatments (Table 1$)$. During d0-d26, LW treatment showed a significantly $(P<0.05)$ higher final body weight and weight gain than the other treatments except for LF10, resulting a higher metabolic growth rate than all the other treatments. No significant $(P>0.05)$ difference in weight gain and metabolic growth rate was detected between all treatments during period $\mathrm{d} 26-\mathrm{d} 44$. Repeated measures ANOVA analysis revealed that both treatment and time had a significant $(P<0.05)$ effect on the fish weight gain and metabolic growth rate. Moreover, significant interaction between time and treatment concurred with the observed disappearance of significant difference between treatments from period $\mathrm{d} 0-\mathrm{d} 26$ to period $\mathrm{d} 27-\mathrm{d} 44$.

Table 1 Growth performance of all treatments during d0-d26 and d26-d44

\begin{tabular}{|c|c|c|c|c|c|c|c|c|c|c|c|}
\hline \multirow[t]{2}{*}{ Time } & \multirow[t]{2}{*}{ Growth parameter } & \multicolumn{6}{|c|}{ Treatment } & \multirow[t]{2}{*}{ SEM } & \multicolumn{3}{|l|}{$P$ value } \\
\hline & & Ctrl & DF5 & DF10 & LF5 & LF10 & LW & & Treatment & Time & $\begin{array}{l}\text { Treat- } \\
\text { ment* } \\
\text { Time }\end{array}$ \\
\hline \multirow[t]{4}{*}{$\mathrm{d} 0-\mathrm{d} 26$} & Initial body weight (g) & 0.57 & 0.58 & 0.58 & 0.56 & 0.62 & 0.57 & 0.02 & $\mathrm{~ns}$ & na & na \\
\hline & Final body weight (g) & $3.12^{\mathrm{b}}$ & $3.05^{\mathrm{b}}$ & $3.06^{\mathrm{b}}$ & $3.01^{\mathrm{b}}$ & $3.30^{\mathrm{ab}}$ & $3.56^{\mathrm{a}}$ & 0.09 & $* *$ & & \\
\hline & Weight gain $(\mathrm{g})$ & $2.55^{\mathrm{b}}$ & $2.46^{\mathrm{b}}$ & $2.48^{\mathrm{b}}$ & $2.45^{\mathrm{b}}$ & $2.67^{\mathrm{ab}}$ & $2.99^{\mathrm{a}}$ & 0.07 & $* *$ & & \\
\hline & Metabolic growth rate $\left(\mathrm{g} \mathrm{kg}^{-0.8} \mathrm{~d}^{-1}\right)$ & $20.31^{\mathrm{b}}$ & $19.63^{\mathrm{b}}$ & $19.84^{\mathrm{b}}$ & $19.85^{\mathrm{b}}$ & $20.14^{\mathrm{b}}$ & $22.60^{\mathrm{a}}$ & 0.31 & $* * *$ & & \\
\hline \multirow[t]{4}{*}{ d26-d44 } & Initial body weight $(\mathrm{g})$ & $3.12^{\mathrm{b}}$ & $3.07^{\mathrm{b}}$ & $3.11^{\mathrm{b}}$ & $3.07^{\mathrm{b}}$ & $3.33^{\mathrm{ab}}$ & $3.56^{\mathrm{a}}$ & 0.08 & $* *$ & na & na \\
\hline & Final body weight (g) & 8.71 & 8.68 & 8.68 & 8.59 & 9.32 & 9.89 & 0.31 & $\#$ & & \\
\hline & Weight gain $(\mathrm{g})$ & 5.59 & 5.61 & 5.58 & 5.53 & 5.99 & 6.33 & 0.24 & ns & & \\
\hline & Metabolic growth rate $\left(\mathrm{g} \mathrm{kg}^{-0.8}\right.$ day $\left.^{-1}\right)$ & 20.8 & 21.09 & 20.81 & 20.86 & 21.16 & 21.23 & 0.45 & ns & & \\
\hline \multirow[t]{2}{*}{$\mathrm{d} 0-\mathrm{d} 44$} & Weight gain $(\mathrm{g})$ & $4.07^{\mathrm{b}}$ & $4.04^{\mathrm{b}}$ & $4.03^{\mathrm{b}}$ & $3.99^{\mathrm{b}}$ & $4.33^{\mathrm{ab}}$ & $4.66^{\mathrm{a}}$ & 0.13 & * & $* * *$ & ns \\
\hline & Metabolic growth rate $\left(\mathrm{g} \mathrm{kg}^{-0.8} \mathrm{day}^{-1}\right)$ & $20.56^{\mathrm{b}}$ & $20.36^{\mathrm{b}}$ & $20.33^{\mathrm{b}}$ & $20.36^{\mathrm{b}}$ & $20.65^{\mathrm{b}}$ & $21.92^{\mathrm{a}}$ & 0.27 & $* *$ & * & * \\
\hline
\end{tabular}

SEM standard error of the mean, $n s$ not significant, $n a$ not applied

${ }^{\#} P<0.1, * P<0.05, * * P<0.01, * * * P<0.001$. The different superscript letters indicated the significant difference between treatments 
Overall, LW resulted in a higher weight gain and metabolic growth rate than the Ctrl, fish from LF10 treatment achieved similar growth as LW, whereas dietary supplementation of dead biofloc at 5 and $10 \%$ (DF5 and DF10) or live biofloc at $5 \%$ (LF5) had no effect on fish growth as compared with the Ctrl treatment.

\section{Gut Microbial Diversity on Day 0, 26 and 49}

A total of 183 gut samples were analyzed from the six treatment groups at $\mathrm{d} 0, \mathrm{~d} 26$ and $\mathrm{d} 49$, which revealed the presence of 1298 different OTUs. Among them, 611 OTUs were detected in two or more samples, which were used for further analysis. The alpha diversity indexes are shown in Fig. 2 and the statistical analysis result is shown in Table S1. At both d26 and d49, LW showed the highest alpha diversity indexes and the lowest variations of the prokaryotic communities in all treatment groups. At d26, LW showed significantly $($ FDR $<0.05)$ higher diversity for the Shannon, PD whole tree and Chao1 indexes than $\mathrm{Ctrl}$, while the other treatments had similar alpha diversity indexes as Ctrl. At d49, LW only showed significantly higher (FDR < 0.05) diversity than Ctrl for the Shannon index, but not for the PD whole tree and Chaol indexes. Still, fish fed with ex-situ biofloc (LF and DF) had similar alpha diversity for all indexes as Ctrl treatment at d49. We also compared the alpha diversity shift over time, which revealed that fish receiving in-situ biofloc or exsitu live biofloc in LW, LF5 and LF10 showed a significant $($ FDR $<0.05)$ increase from $\mathrm{d} 0$ to $\mathrm{d} 26$ and then a significant $($ FDR $<0.05)$ decrease from d26 to d49 in the Shannon, Chao1 and PD whole tree indexes. This resulted in a similar alpha diversity index between $\mathrm{d} 0$ and $\mathrm{d} 49$ for fish fed with ex-situ live biofloc while LW still showed significantly higher diversity at $\mathrm{d} 49$ than $\mathrm{d} 0$ for the Shannon and PD whole tree indexes but not in Chaol index. On the other hand, fish from DF5 and DF10 did not show significant change in prokaryotic diversity over time. a

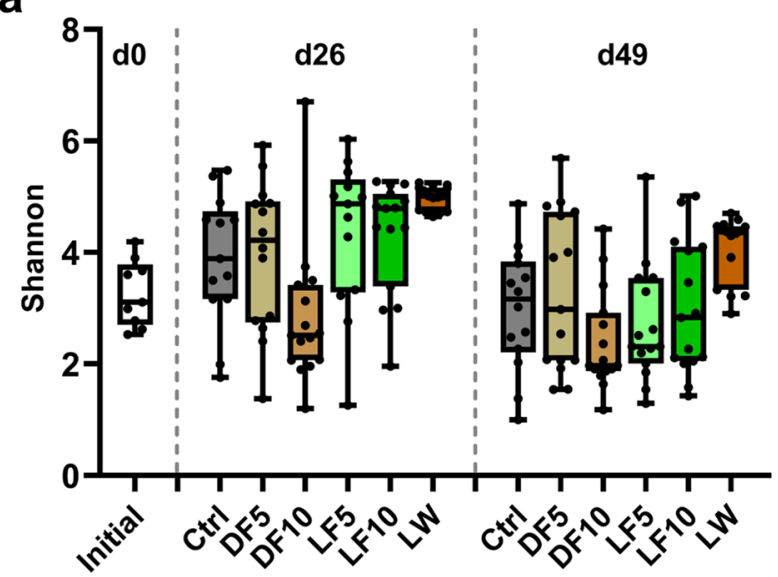

C

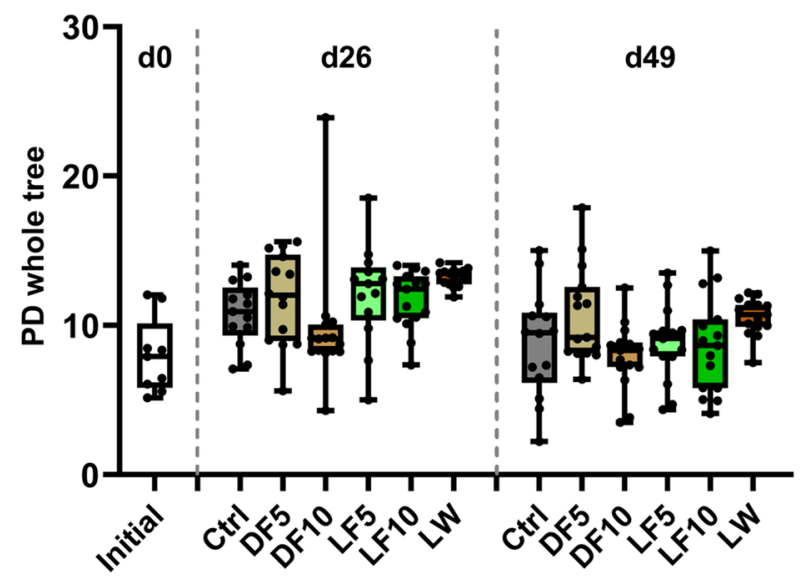

b

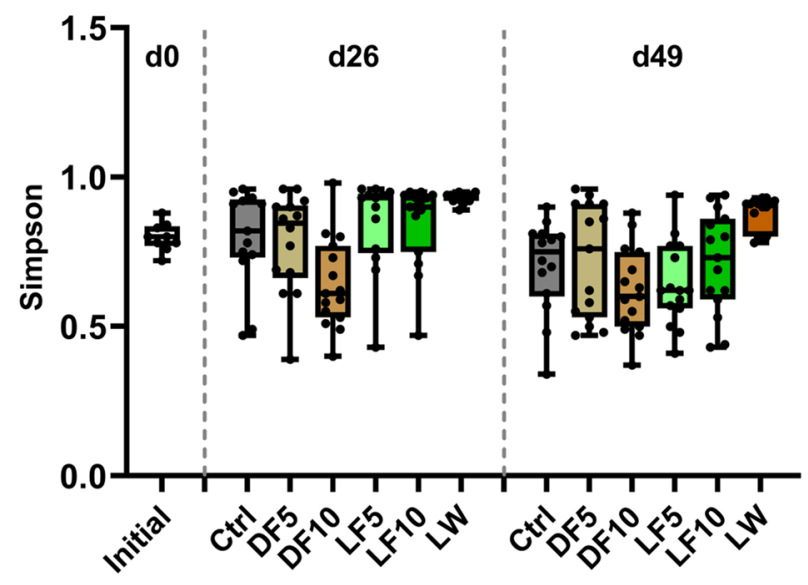

d

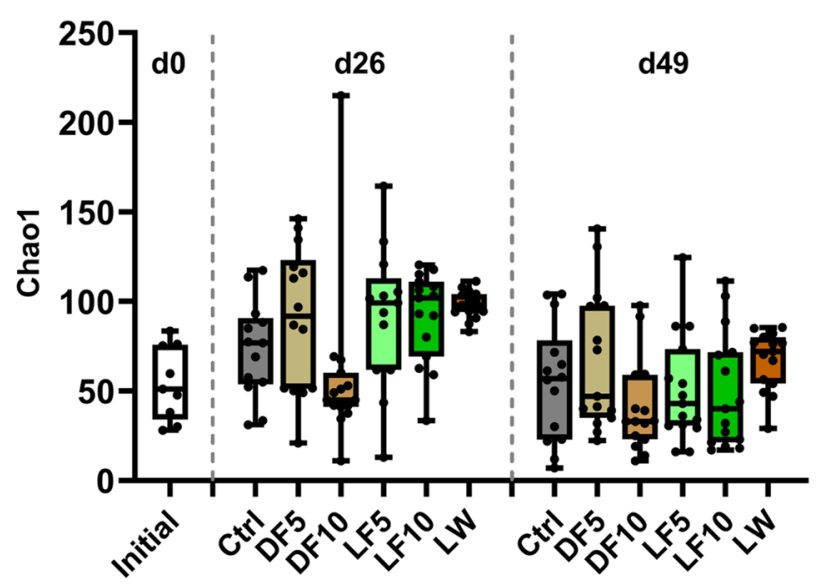

Fig. 2 Changes in alpha diversity indexes of Nile tilapia gut prokaryotic community from six treatments at day 0, 26 and 49. a Shannon index, b Simpson index, c PD whole tree index, $\mathbf{d}$ Chao1 index 


\section{Gut Prokaryotic Community Distribution}

To investigate the distribution of the intestinal prokaryotic community, RDA was performed on the relative abundance of genera using collection timepoint, treatment, fish body weight and tank number as explanatory variables (Fig. 3a). Together these variables accounted for $36.3 \%$ variation in the data, with a significant $($ FDR $<0.05)$ conditional effect of variables "d26_LW" (9.6\% variation), "d49_LW" (5.9\% variation), and "d26_DF" (1.2\% variation). There was a clear separation of samples by collection timepoint and LW treatment. Similarly, the PCoA results also indicated the separation of samples based on collection timepoint and separation of the LW treatment from the other treatments at both $\mathrm{d} 26$ and $\mathrm{d} 49$ based on weighted UniFrac analysis (Fig. S1). To remove the effect of time, we set the variable "timepoint" as covariate and repeated the RDA analysis with treatment as explanatory variable (Fig. 3b). The result again showed a significant conditional effect of $\mathrm{LW}$, and a trend effect $(F D R=0.06)$ of LF, with a clear separation of LW from the other treatments.

The ANOSIM test showed that all treatments resulted in unique $(P<0.05)$ gut microbiota profiles of prokaryotic community composition based on weighted Unifrac data on d26 (Table S2). On d49, only DF and LW prokaryotic community composition was significantly $(P<0.05)$ different from Ctrl when weighted UniFrac distances were compared.

\section{Gut Prokaryotic Community Composition}

In all the gut samples, a total of 487 genera was identified, of which the genera detected in more than $95 \%$ of the samples were referred to as the core genera (Fig. 4). The four core genera, namely Cetobacterium, Halomonas, Mycobacterium and an unidentified genus within the family Peptostreptococcaceae, varied slightly over each timepoint. To be noticed, the four core genera also had high average relative abundance for all the gut samples, Cetobacterium (average RA $=49 \%$, range $0.8-96 \%$, prevalence $=100 \%$ ), Mycobacterium (average RA $=7 \%$, range 0-26\%; prevalence $=99 \%$ ), an unidentified genus within the family Peptostreptococcaceae (average RA $=5 \%$, range $0-43 \%$, prevalence $=97 \%$ ), and Halomonas (average RA $=4 \%$, range $0-29 \%$, prevalence $=97 \%$ ). However, the number of core genera for all treatments decreased from thirteen at $\mathrm{d} 26$ to three at $\mathrm{d} 49$. The shift of core genera was consistent with the result that the prevalence of the main genera oscillated with time and between treatment groups (Fig. S2).

There was no significant difference in the relative abundance of gut genera between 5\% and $10 \%$ supplementation of ex-situ biofloc in both DF and LF treatments. Therefore, the DF5 and DF10 treatments were pooled as DF, and LF5 and LF10 treatments were pooled as LF. There were 77 genus level taxa on d26, and 44 genus level taxa on d49 varied significantly $($ FDR $<0.05)$ in relative abundance between all treatments (i.e. Ctrl, LF, DF and LW). Thirtyfive of these differentially abundant taxa were detected at both timepoints (Table 2, with the full taxonomic classification of the taxa provided in Table S3), indicating that the treatment effects on these taxa were relative stable over time. Among these 35 taxa, the core genera Cetobacterium and Mycobacterium were also detected with more than 95\% prevalence in the gut samples. a

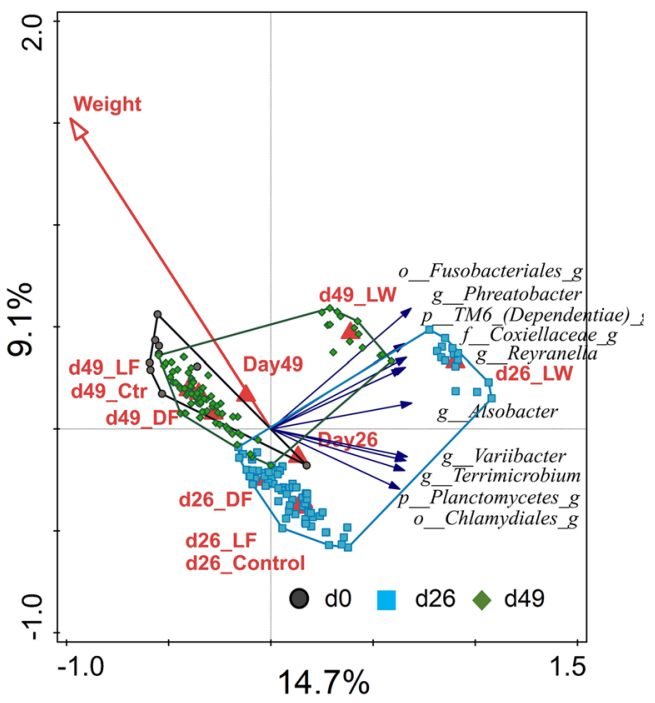

b

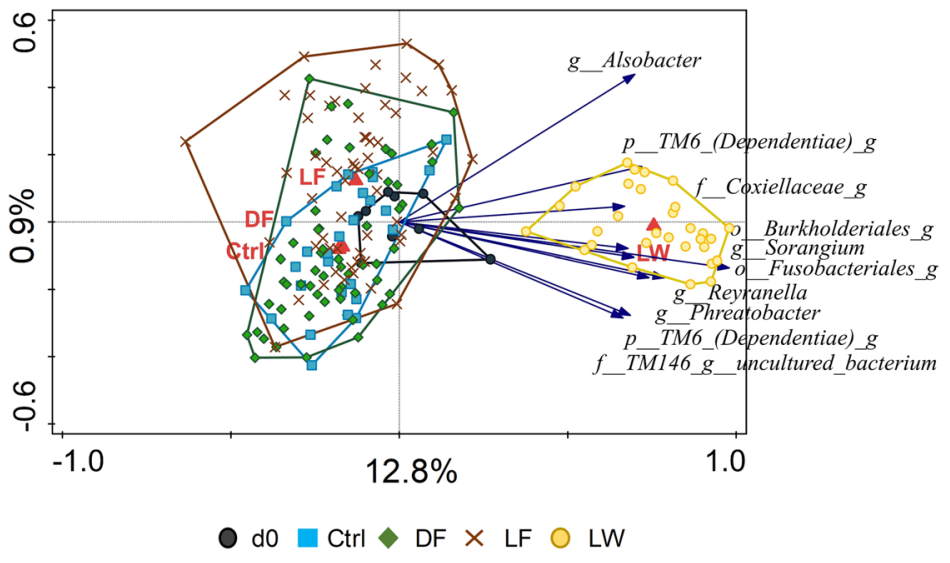

Fig. 3 RDA displaying 10 best fitting genus level taxa to explain the variations in gut prokaryotes. a Samples color coded by timepoint; $\mathbf{b}$ samples color coded by treatment group with timepoint as covariate 
a

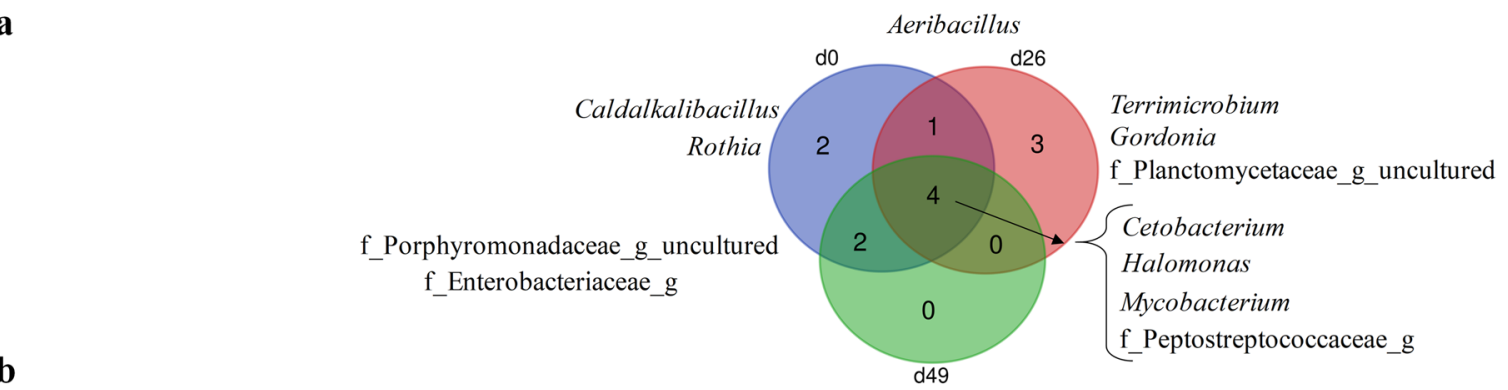

b

Phreatobacter, Meganema, Macellibacteroides, Gemmata, Bradyrhizobium, Reyranella, Alsobacter,

f_Parachlamydiaceae_g, f_Coxiellaceae_g,

f_Porphyromonadaceae_g_uncultured,

f_Enterobacteriaceae_g,

f_Acidimicrobiales_Incertae_Sedis_g_Candidatus_Microthrix

c_uncultured_Candidatus_Saccharibacteria_g,

o_JG30-KF-C-CM45 f_uncultured_soil_bacterium_g,

o_Fusobacteriales_g, o_Burkholderiales_g,

o_JG30_KF_CM45_g, o_Chlamydiales_g,

p_TM6_Dependentiae_g, NA, p_Saccharibacteria_g

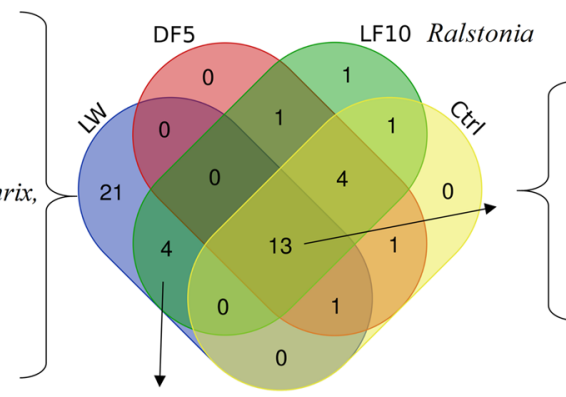

Gordonia, Aeribacillus, Halomonas, Variibacter, Cetobacterium, Rhodococcus, Terrimicrobium, Planctomyces,

Mycobacterium, f_Planctomycetaceae_g, f_Peptostreptococcaceae_g, f_Planctomycetaceae_g_uncultured, p_Planctomycetes_g,

Nordella,Pir4_lineage, f_Microbacteriaceae_g_unknown,

f_MNG7_g_uncultured_bacterium

c

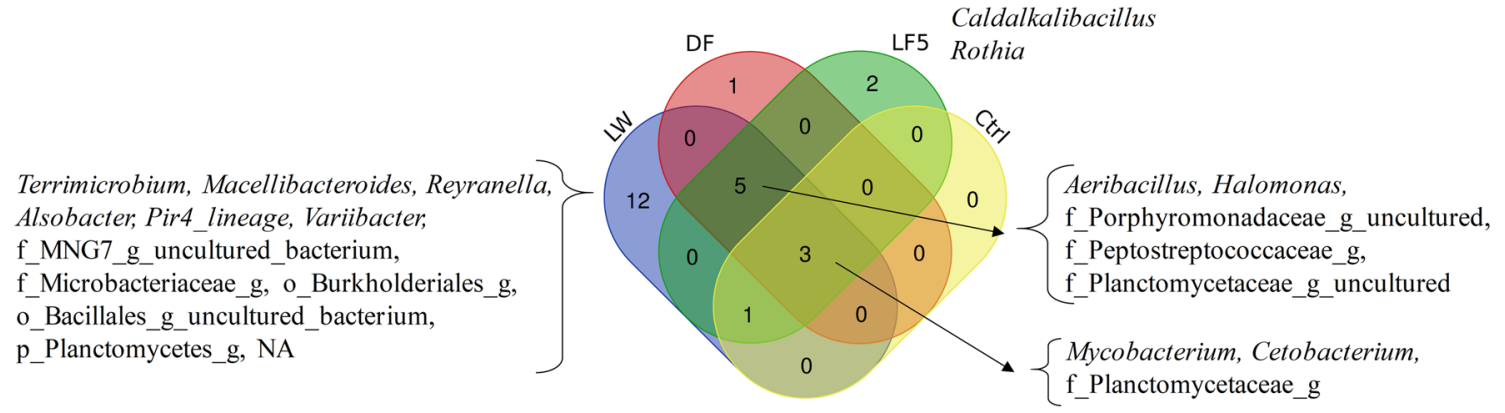

Fig. 4 Venn diagrams showing shared genus level taxa found in more than 95\% of samples a within three sampling timepoints, b on d26, and a on $\mathrm{d} 49$

Moreover, pairwise comparisons of relative abundances at genus level for each of the treatment indicated no significant $($ FDR $<0.05)$ differences between LF vs. Ctrl and DF vs. Ctrl on d26 and d49. However, differentially abundant taxa could be found between LW and Ctrl, including 63 taxa on d 26 and 30 taxa on d49. There were 21 taxa differing between LW and Ctrl on both d 26 and d49, which is shown in Table 3 . The specific taxa that only significantly varied in LW vs. Ctrl but not in LW vs. LF groups were Cetobacterium, Cupriavidus, Iamia and unidentified genera of the family Brevinemataceae on d26, and Turicibacter and unidentified genera of the family Peptostreptococcaceae and the order Rhizobiales on d49 (Table S4). This finding suggested the unique and specific effect of the LW treatment on the gut microbial community in Nile tilapia.

\section{Water and Feed Microbial Community}

The harvested bioflocs, feed samples and filtered tank water showed a distinct prokaryotic community composition when compared with the gut samples according to PCoA plot (Fig. S3). There was a clear separation (FDR < 0.05) among water samples based on collection timepoint, and treatments were clustered within the same timepoint (Fig. 5a). The ANOSIM results showed that DF and LF had similar prokaryotic community in the water with Ctrl on the three timepoints (Table S5a). On the other hand, LW exhibited a significantly different water prokaryotic community on d26 and d49 when compared with all the other treatments. The LW water was dominant with a genus belonging to the order 195up (average RA $=16 \%$ ), 
Table 2 Differentially (FDR <0.05) abundant genera taxa of intestinal prokaryotes between treatments on both d26 and d49

\begin{tabular}{|c|c|c|c|c|c|c|c|c|c|c|}
\hline \multirow{2}{*}{ Taxonomy } & \multicolumn{2}{|c|}{ FDR_P } & \multicolumn{4}{|c|}{ Mean average relative abundance $\mathrm{d} 26$} & \multicolumn{4}{|c|}{ Mean average relative abundance $\mathrm{d} 49$} \\
\hline & $\mathrm{d} 26$ & d49 & Control & $\mathrm{DF}$ & LF & LW & Control & DF & LF & LW \\
\hline Cetobacterium $\dagger$ & $8.29 \mathrm{E}-05$ & 4.92E-03 & 0.4394 & 0.5921 & 0.3140 & 0.1278 & 0.6091 & 0.6200 & 0.6215 & 0.3268 \\
\hline Terrimicrobium & $1.07 \mathrm{E}-07$ & $1.32 \mathrm{E}-06$ & 0.0395 & 0.0243 & 0.0344 & 0.2684 & 0.0050 & 0.0075 & 0.0066 & 0.0884 \\
\hline Mycobacterium $\dagger$ & $3.96 \mathrm{E}-04$ & $2.54 \mathrm{E}-03$ & 0.0773 & 0.0538 & 0.0960 & 0.1231 & 0.0312 & 0.0554 & 0.0399 & 0.1223 \\
\hline f_Planctomycetaceae_g_uncultured & $3.09 \mathrm{E}-06$ & $1.98 \mathrm{E}-03$ & 0.0387 & 0.0239 & 0.0317 & 0.0938 & 0.0091 & 0.0130 & 0.0112 & 0.0356 \\
\hline f_Planctomycetaceae_g & $1.21 \mathrm{E}-06$ & $1.30 \mathrm{E}-04$ & 0.0052 & 0.0042 & 0.0056 & 0.0254 & 0.0146 & 0.0211 & 0.0173 & 0.0774 \\
\hline$f_{-} M N G 7 \_g \_u n c u l t u r e d \_b a c t e r i u m t_{\dagger}^{\wedge}$ & $9.43 \mathrm{E}-07$ & $2.96 \mathrm{E}-07$ & 0.0035 & 0.0046 & 0.0050 & 0.0211 & 0.0006 & 0.0012 & 0.0014 & 0.0093 \\
\hline$p \_$Planctomycetes_ $g^{\wedge}$ & $2.67 \mathrm{E}-08$ & $6.91 \mathrm{E}-05$ & 0.0031 & 0.0024 & 0.0046 & 0.0194 & 0.0004 & 0.0010 & 0.0010 & 0.0052 \\
\hline o_Burkholderiales_g*^ & $2.48 \mathrm{E}-08$ & $2.96 \mathrm{E}-07$ & 0.0029 & 0.0015 & 0.0025 & 0.0180 & 0.0012 & 0.0022 & 0.0016 & 0.0442 \\
\hline$N A^{* \wedge}$ & $2.65 \mathrm{E}-05$ & $1.27 \mathrm{E}-06$ & 0.0113 & 0.0037 & 0.0052 & 0.0152 & 0.0007 & 0.0033 & 0.0012 & 0.0130 \\
\hline Variibacter $^{\wedge}$ & $6.71 \mathrm{E}-07$ & $2.96 \mathrm{E}-07$ & 0.0050 & 0.0033 & 0.0057 & 0.0140 & 0.0004 & 0.0013 & 0.0009 & 0.0074 \\
\hline Pir4_lineage $t^{\wedge}$ & $2.04 \mathrm{E}-04$ & $1.57 \mathrm{E}-03$ & 0.0038 & 0.0055 & 0.0066 & 0.0136 & 0.0006 & 0.0016 & 0.0011 & 0.0038 \\
\hline$o \_J G 30 \_K F \_C M 45 \_g^{*}$ & 7.79E-06 & $1.43 \mathrm{E}-04$ & 0.0047 & 0.0023 & 0.0023 & 0.0099 & 0.0004 & 0.0009 & 0.0006 & 0.0036 \\
\hline$o \_C h l a m y d i a l e s \_g *$ & $3.55 \mathrm{E}-07$ & $3.35 \mathrm{E}-02$ & 0.0018 & 0.0012 & 0.0022 & 0.0084 & 0.0000 & 0.0001 & 0.0000 & 0.0006 \\
\hline$f_{-}$Microbacteriaceae $g^{\wedge}$ & $1.29 \mathrm{E}-06$ & $6.37 \mathrm{E}-08$ & 0.0026 & 0.0019 & 0.0035 & 0.0079 & 0.0007 & 0.0014 & 0.0009 & 0.0132 \\
\hline Nordella & $1.71 \mathrm{E}-02$ & $4.30 \mathrm{E}-04$ & 0.0028 & 0.0019 & 0.0027 & 0.0045 & 0.0000 & 0.0003 & 0.0002 & 0.0013 \\
\hline f_Rhodobacteraceae_g & $2.82 \mathrm{E}-02$ & $1.74 \mathrm{E}-02$ & 0.0024 & 0.0038 & 0.0031 & 0.0004 & 0.0018 & 0.0023 & 0.0020 & 0.0000 \\
\hline Archaea_g & $2.00 \mathrm{E}-06$ & $1.79 \mathrm{E}-02$ & 0.0162 & 0.0139 & 0.0171 & 0.0004 & 0.0037 & 0.0076 & 0.0048 & 0.0009 \\
\hline f_Porphyromonadaceae_g_uncultured & $2.72 \mathrm{E}-07$ & $1.59 \mathrm{E}-02$ & 0.0012 & 0.0007 & 0.0088 & 0.0332 & 0.0695 & 0.0395 & 0.0534 & 0.0952 \\
\hline Alsobacter*^ & $1.58 \mathrm{E}-08$ & $2.28 \mathrm{E}-10$ & 0.0010 & 0.0005 & 0.0014 & 0.0056 & 0.0000 & 0.0003 & 0.0003 & 0.0032 \\
\hline Reyranella*^ & $1.43 \mathrm{E}-08$ & $7.92 \mathrm{E}-12$ & 0.0008 & 0.0014 & 0.0008 & 0.0143 & 0.0003 & 0.0001 & 0.0000 & 0.0041 \\
\hline g_Candidatus_Microthrix $*$ & $2.15 \mathrm{E}-06$ & $1.93 \mathrm{E}-06$ & 0.0006 & 0.0006 & 0.0010 & 0.0031 & 0.0000 & 0.0001 & 0.0001 & 0.0014 \\
\hline$f \_$Geodermatophilaceae_g_uncultured & $4.78 \mathrm{E}-04$ & $7.89 \mathrm{E}-05$ & 0.0003 & 0.0003 & 0.0008 & 0.0015 & 0.0000 & 0.0003 & 0.0001 & 0.0011 \\
\hline Meganema* & $4.90 \mathrm{E}-11$ & $1.17 \mathrm{E}-02$ & 0.0002 & 0.0004 & 0.0001 & 0.0040 & 0.0000 & 0.0000 & 0.0000 & 0.0005 \\
\hline Iamia & $5.59 \mathrm{E}-03$ & $2.96 \mathrm{E}-03$ & 0.0001 & 0.0005 & 0.0011 & 0.0014 & 0.0003 & 0.0008 & 0.0005 & 0.0036 \\
\hline Macellibacteroides ${ }^{* \wedge}$ & $1.17 \mathrm{E}-12$ & $2.67 \mathrm{E}-03$ & 0.0000 & 0.0000 & 0.0020 & 0.0029 & 0.0066 & 0.0021 & 0.0146 & 0.0065 \\
\hline Deefgea & $1.58 \mathrm{E}-08$ & $6.57 \mathrm{E}-03$ & 0.0000 & 0.0000 & 0.0007 & 0.0024 & 0.0012 & 0.0007 & 0.0018 & 0.0107 \\
\hline Sorangium & $1.04 \mathrm{E}-07$ & $2.96 \mathrm{E}-07$ & 0.0001 & 0.0000 & 0.0004 & 0.0010 & 0.0000 & 0.0005 & 0.0003 & 0.0037 \\
\hline p_TM6_Dependentiae_ ${ }^{*} *$ & $3.92 \mathrm{E}-11$ & $1.30 \mathrm{E}-04$ & 0.0001 & 0.0000 & 0.0002 & 0.0028 & 0.0000 & 0.0000 & 0.0000 & 0.0005 \\
\hline o_Fusobacteriales_g* & $1.17 \mathrm{E}-12$ & $1.85 \mathrm{E}-13$ & 0.0002 & 0.0000 & 0.0002 & 0.0081 & 0.0000 & 0.0000 & 0.0000 & 0.0086 \\
\hline$f \_T M 146 \_g \_u n c u l t u r e d \_b a c t e r i u m$ & $1.34 \mathrm{E}-06$ & $3.12 \mathrm{E}-08$ & 0.0000 & 0.0000 & 0.0000 & 0.0009 & 0.0000 & 0.0005 & 0.0002 & 0.0046 \\
\hline$p_{-}$TM6_Dependentiae_uncultured_g & $6.52 \mathrm{E}-04$ & $1.01 \mathrm{E}-08$ & 0.0001 & 0.0000 & 0.0000 & 0.0006 & 0.0000 & 0.0000 & 0.0000 & 0.0009 \\
\hline f_Holosporaceae_g_uncultured & $1.19 \mathrm{E}-03$ & $1.36 \mathrm{E}-03$ & 0.0000 & 0.0000 & 0.0000 & 0.0004 & 0.0000 & 0.0000 & 0.0000 & 0.0005 \\
\hline${ }_{\wedge}$ _Bacillales_g_uncultured_bacterium & $8.29 \mathrm{E}-05$ & $1.27 \mathrm{E}-06$ & 0.0002 & 0.0000 & 0.0008 & 0.0000 & 0.0001 & 0.0011 & 0.0006 & 0.0057 \\
\hline$f \_$Rickettsiaceae_g & $9.85 \mathrm{E}-05$ & $3.73 \mathrm{E}-02$ & 0.0022 & 0.0016 & 0.0020 & 0.0000 & 0.0010 & 0.0020 & 0.0019 & 0.0002 \\
\hline c_SBR2076_g & $2.37 \mathrm{E}-05$ & $1.24 \mathrm{E}-02$ & 0.0037 & 0.0026 & 0.0036 & 0.0000 & 0.0019 & 0.0040 & 0.0034 & 0.0001 \\
\hline
\end{tabular}

Core taxa in d26 and d49; * core taxa in LW d26; ${ }^{\dagger}$ core taxa in LW d49; ${ }^{\star}$ core taxa in LF+LW, core taxa means the taxa detected in more than $95 \%$ of the samples. Values are colored based on graded color scale where red indicates the lowest value, yellow indicates the percentile, and green indicates the highest value

while the water from DF, LF and Ctrl was dominant with Cetobacterium (average RA $=22 \%$ ) (Fig. 5c). The RDA plot implied that the variations in water samples between different sampling timepoints were caused by low abundant genera instead of the dominant genera shown in Fig. 5c.

In this study, bioflocs were harvested from a biofloc production system to make the LF and DF feed by mixing with the control diet which was presented as LW/Ctrl feed in 
Table 3 Differentially $(F D R<0.05)$ abundant genera taxa in pairwise comparisons of intestinal prokaryotes between LW and Ctrl on both d26 and $\mathrm{d} 49$

\begin{tabular}{|c|c|c|c|c|c|c|}
\hline \multirow{2}{*}{ Taxonomy } & \multicolumn{2}{|c|}{ FDR_P } & \multicolumn{2}{|c|}{$\begin{array}{l}\text { Average relative abundance } \\
\text { d26 }\end{array}$} & \multicolumn{2}{|c|}{$\begin{array}{c}\text { Average relative abundance } \\
\text { d49 }\end{array}$} \\
\hline & d26 & d49 & Control & $\mathbf{L W}$ & Control & $\mathbf{L W}$ \\
\hline f_TM146_g_uncultured_bacterium & $1.33 \mathrm{E}-02$ & $3.12 \mathrm{E}-04$ & 0 & 0.0009 & 0 & 0.0046 \\
\hline o_Fusobacteriales_g* & $1.29 \mathrm{E}-04$ & $3.12 \mathrm{E}-04$ & 0.0002 & 0.0081 & 0 & 0.0086 \\
\hline Reyranella* & $1.29 \mathrm{E}-04$ & $8.08 \mathrm{E}-04$ & 0.0008 & 0.0143 & 0.0003 & 0.0041 \\
\hline Sorangium & $2.90 \mathrm{E}-03$ & $3.12 \mathrm{E}-04$ & 0.0001 & 0.001 & 0 & 0.0037 \\
\hline Iamia & $1.69 \mathrm{E}-03$ & $2.06 \mathrm{E}-02$ & 0.0001 & 0.0014 & 0.0003 & 0.0036 \\
\hline g_Terrimicrobium & $1.29 \mathrm{E}-04$ & $1.95 \mathrm{E}-04$ & 0.0395 & 0.2684 & 0.005 & 0.0884 \\
\hline$p \_$Planctomycetes_g & $1.29 \mathrm{E}-04$ & $9.18 \mathrm{E}-04$ & 0.0031 & 0.0194 & 0.0004 & 0.0052 \\
\hline o_Burkholderiales_g* & $1.29 \mathrm{E}-04$ & $1.91 \mathrm{E}-04$ & 0.0029 & 0.018 & 0.0012 & 0.0442 \\
\hline$f \_M N G 7 \_g \_u n c u l t u r e d \_b a c t e r i u m$ & 1.49E-04 & $1.91 \mathrm{E}-04$ & 0.0035 & 0.0211 & 0.0006 & 0.0093 \\
\hline Alsobacter* & $1.29 \mathrm{E}-04$ & $1.91 \mathrm{E}-04$ & 0.001 & 0.0056 & 0 & 0.0032 \\
\hline g_Candidatus_Microthrix* & $2.07 \mathrm{E}-04$ & $8.86 \mathrm{E}-03$ & 0.0006 & 0.0031 & 0 & 0.0014 \\
\hline f_Planctomycetaceae $g$ & $2.69 \mathrm{E}-04$ & $1.08 \mathrm{E}-03$ & 0.0052 & 0.0254 & 0.0146 & 0.0774 \\
\hline f_Geodermatophilaceae_g_uncultured & $3.41 \mathrm{E}-03$ & 4.47E-03 & 0.0003 & 0.0015 & 0 & 0.0011 \\
\hline Pir4_lineage & $2.07 \mathrm{E}-04$ & $2.00 \mathrm{E}-02$ & 0.0038 & 0.0136 & 0.0006 & 0.0038 \\
\hline$f \_$Microbacteriaceae_g & $8.09 \mathrm{E}-04$ & $1.91 \mathrm{E}-04$ & 0.0026 & 0.0079 & 0.0007 & 0.0132 \\
\hline Variibacter & $4.30 \mathrm{E}-04$ & $1.91 \mathrm{E}-04$ & 0.005 & 0.014 & 0.0004 & 0.0074 \\
\hline f_Planctomycetaceae_g_uncultured & $2.01 \mathrm{E}-03$ & $6.11 \mathrm{E}-03$ & 0.0387 & 0.0938 & 0.0091 & 0.0356 \\
\hline o_JG30-KF-CM45_g & $1.64 \mathrm{E}-02$ & 4.47E-03 & 0.0047 & 0.0099 & 0.0004 & 0.0036 \\
\hline f_Peptostreptococcaceae $g \dagger$ & $2.71 \mathrm{E}-03$ & $2.00 \mathrm{E}-02$ & 0.0774 & 0.0335 & 0.0105 & 0.0279 \\
\hline Cetobacterium ${ }^{\dagger}$ & $1.45 \mathrm{E}-02$ & $8.06 \mathrm{E}-03$ & 0.4394 & 0.1278 & 0.6091 & 0.3268 \\
\hline f_Rhodobacteraceae_g & $2.00 \mathrm{E}-02$ & $4.56 \mathrm{E}-02$ & 0.0024 & 0.0004 & 0.0018 & 0 \\
\hline
\end{tabular}

$\dagger$ core taxa in all treatments on d26 and d49; *core taxa in LW on d26 and d49; core taxa means the taxa detected in more than 95\% of the samples. Values are colored based on graded color scale where red indicates the lowest value, yellow indicates the percentile, and green indicates the highest value

Fig. 5b. The prokaryotic community in LW/Ctrl feed were clustered together at all the three sampling timepoints and showed significant $(P<0.05)$ difference with the LF and DF feed according to ANOSIM test (Table S5b). The prokaryotic community in bioflocs changed over time and showed significant difference with the LF feed and DF feed on each timepoint. On the other hand, no significant differences were observed between the DF and LF feed at all the three timepoints. The LW/Ctrl feed was dominant with Cetobacterium (average $\mathrm{RA}=7.6 \%$ ) and a genus belonging to the order 195up (average RA $=4.3 \%$ ). The LF and DF feed were dominant with a genus belonging to the order 195up (average $\mathrm{RA}=14 \%$ ), a genus belonging to family Comamonadaceae (average RA $=7.9 \%$ ) and Mycobacterium (average $\mathrm{RA}=6.2 \%)$. Like the water samples, the variations between feed samples were caused by low abundant genera instead of the dominant genera as shown in Fig. 5d.

Moreover, we compared the bioflocs $(n=10)$, LW filtered water $(n=17)$ and LW fish gut $(n=30)$ samples collected on both $\mathrm{d} 26$ and $\mathrm{d} 49$ (Fig. S4). There were 25 taxa that were shared between bioflocs, LW filtered water and LW gut samples. Among these taxa Mycobacterium, Terrimicrobium, Cetobacterium and unidentified genera within the families Planctomycetaceae and Porphyromonadaceae showed 100\% prevalence in all the samples and had higher average relative abundance in the gut of Nile tilapia in the LW treatment than in the gut of fish from other treatments, which suggests that these taxa might originate from the bioflocs or LW tank water.

\section{Discussion}

\section{LW Promoted Tilapia Growth, DF and LF Showed No Enhancement in Growth}

In this study, fish cultured in the in-situ biofloc (LW) had a weight gain of $15 \%$ higher than the Ctrl that were not 

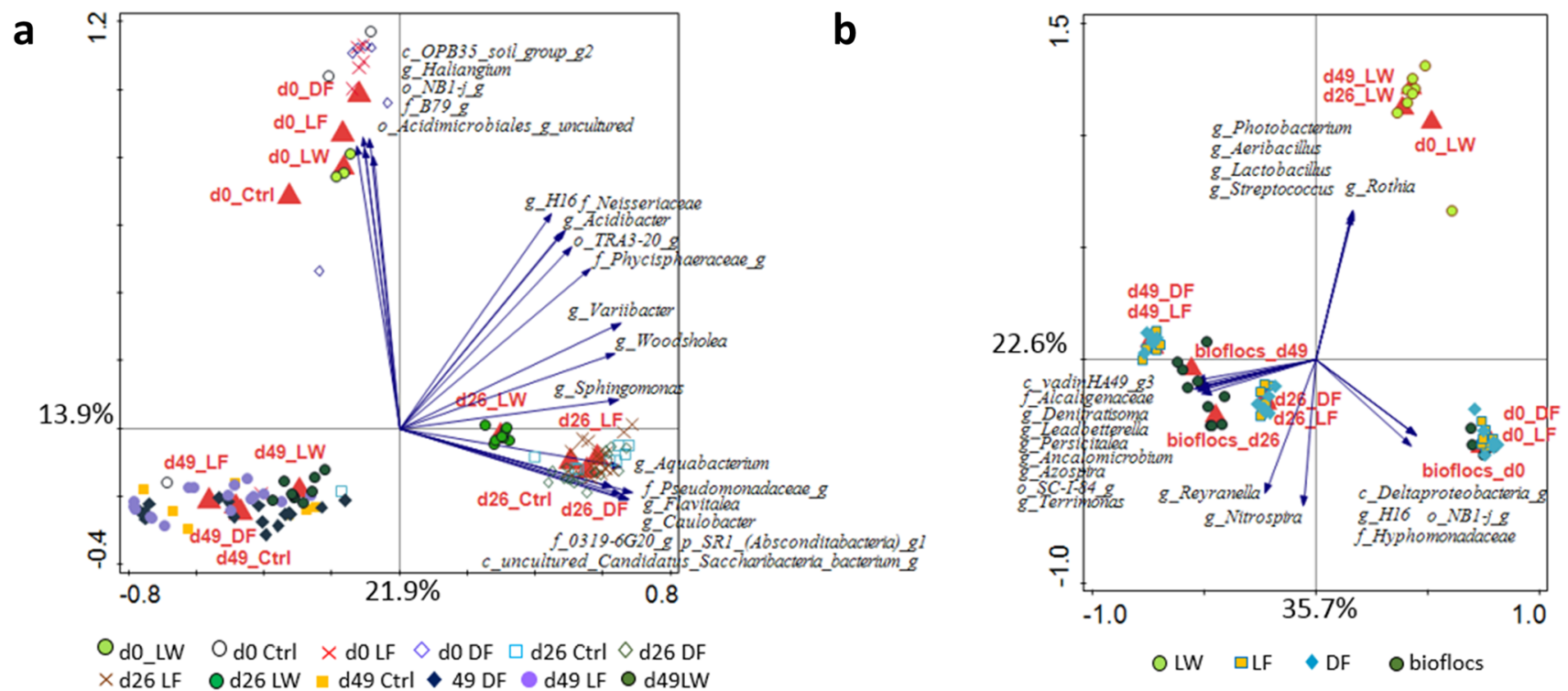

C

\begin{tabular}{|c|c|c|c|c|c|c|c|}
\hline \multirow[b]{2}{*}{ Taxonomy } & \multicolumn{3}{|c|}{ LW } & \multicolumn{4}{|c|}{ Average relative abundance } \\
\hline & do & d26 & d49 & LW & DF & LF & Ctrl \\
\hline o_195up_g & 0.006 & 0.302 & 0.185 & 0.164 & 0.067 & 0.054 & 0.049 \\
\hline$f_{-}$Saprospiraceae & 0.167 & 0.022 & 0.066 & 0.085 & 0.028 & 0.023 & 0.021 \\
\hline g_Cetobacterium & 0.015 & 0.024 & 0.107 & 0.048 & 0.202 & 0.218 & 0.238 \\
\hline$f \_C o m a m o n a d a c e a e \_g$ & 0.071 & 0.025 & 0.031 & 0.042 & 0.058 & 0.058 & 0.071 \\
\hline g_Mycobacterium & 0.049 & 0.026 & 0.046 & 0.040 & 0.035 & 0.043 & 0.028 \\
\hline$f_{-}$Planctomycetaceae_g & 0.003 & 0.019 & 0.087 & 0.036 & 0.026 & 0.025 & 0.020 \\
\hline f_Cytophagaceae & 0.017 & 0.044 & 0.038 & 0.033 & 0.018 & 0.016 & 0.012 \\
\hline$f_{-} M N G 7$ & 0.080 & 0.005 & 0.012 & 0.032 & 0.016 & 0.015 & 0.012 \\
\hline$f_{-}$Planctomycetaceae & 0.031 & 0.029 & 0.010 & 0.023 & 0.023 & 0.024 & 0.012 \\
\hline$P_{-} F B P_{-} g 2$ & 0.021 & 0.016 & 0.029 & 0.022 & 0.009 & 0.009 & 0.004 \\
\hline g_Haliangium & 0.055 & 0.000 & 0.001 & 0.018 & 0.013 & 0.012 & 0.008 \\
\hline g_Flavobacterium & 0.021 & 0.012 & 0.018 & 0.017 & 0.006 & 0.005 & 0.006 \\
\hline g_Terrimicrobium & 0.000 & 0.024 & 0.023 & 0.016 & 0.009 & 0.011 & 0.007 \\
\hline$f_{-}$Rhodocyclaceae_g & 0.001 & 0.023 & 0.020 & 0.015 & 0.005 & 0.006 & 0.005 \\
\hline g_Planctomyces & 0.011 & 0.017 & 0.009 & 0.013 & 0.013 & 0.013 & 0.009 \\
\hline
\end{tabular}

Fig. 5 Filtered tank water and feed prokaryotic community composition. RDA plots of $\mathbf{a}$ filtered tank water and $\mathbf{b}$ feed samples. Heatmap showing the relative abundance of top 15 abundant genera in $\mathrm{c}$ LW water and other water samples and in $\mathbf{d}$ bioflocs and other feed sam-

exposed to biofloc (Table 1). This enhancement in fish growth falls in the reported range that biofloc systems had $9-27 \%$ higher fish production than the flow-through system or recirculating system [6, 32, 33]. Biofloc grown in the biofloc system were shown to be an effective food source for tilapia $[4,5]$. The fact that biofloc improves fish production is potentially due to the provision of extra food or the enhancement in feed digestion $[1,3]$. However, the growth-promoting effect of dietary supplementation of live and dead biofloc (LF and DF) were not detected in our study. Our studies demonstrated that dietary supplementation of $\gamma$-radiated biofloc at $5 \%$ or $10 \%$ weight base (DF5 and DF10) had no effect on tilapia growth, while the dietary supplementation of live biofloc at $10 \%$ (LF10) showed similar growth as in the Ctrl and LW treatments. In this d

\begin{tabular}{|c|c|c|c|c|c|c|c|}
\hline \multirow[b]{2}{*}{ Taxonamy } & \multicolumn{3}{|c|}{ bioflocs } & \multicolumn{4}{|c|}{ Average relative abundance } \\
\hline & do & d26 & d49 & bioflocs & DF & LF & LW/Ctrl \\
\hline o_195up_g & 0.047 & 0.128 & 0.153 & 0.109 & 0.157 & 0.157 & 0.043 \\
\hline$f_{-}$Saprospiraceae & 0.103 & 0.009 & 0.031 & 0.047 & 0.017 & 0.019 & 0.006 \\
\hline$f_{-}$Comamonadaceae_g & 0.087 & 0.027 & 0.025 & 0.046 & 0.080 & 0.079 & 0.020 \\
\hline$f_{-}$Cytophagaceae & 0.022 & 0.047 & 0.067 & 0.045 & 0.028 & 0.027 & 0.003 \\
\hline$P_{-} F B P_{-} g 2$ & 0.048 & 0.033 & 0.053 & 0.045 & 0.014 & 0.013 & 0.007 \\
\hline g_Terrimicrobium & 0.001 & 0.072 & 0.055 & 0.043 & 0.026 & 0.027 & 0.006 \\
\hline g_Mycobacterium & 0.026 & 0.034 & 0.033 & 0.031 & 0.060 & 0.063 & 0.022 \\
\hline$f_{-}$Planctomycetaceae & 0.038 & 0.034 & 0.021 & 0.031 & 0.027 & 0.022 & 0.006 \\
\hline$f_{-}$Rhodocyclaceae_g & 0.000 & 0.033 & 0.041 & 0.025 & 0.028 & 0.027 & 0.007 \\
\hline g_Gemmata & 0.053 & 0.013 & 0.005 & 0.024 & 0.017 & 0.013 & 0.002 \\
\hline$f \_$Planctomycetaceae_g & 0.003 & 0.015 & 0.047 & 0.022 & 0.020 & 0.015 & 0.003 \\
\hline g_Cetobacterium & 0.014 & 0.022 & 0.026 & 0.021 & 0.015 & 0.015 & 0.076 \\
\hline$f_{-} M N G 7$ & 0.054 & 0.004 & 0.004 & 0.021 & 0.017 & 0.018 & 0.008 \\
\hline g_Haliangium & 0.060 & 0.000 & 0.001 & 0.020 & 0.032 & 0.035 & 0.010 \\
\hline g_Planctomyces & 0.022 & 0.018 & 0.016 & 0.019 & 0.010 & 0.009 & 0.001 \\
\hline
\end{tabular}

ples. Bioflocs were harvested from the biofloc production tank and used to formulate DF and LF feed by mixing with control diet. LW/ Ctrl received the control diet

study, an increasing trend in tilapia growth was observed with the increased dose of ex-situ live biofloc in the feed, which was not observed in the ex-situ dead biofloc feed. This suggested that the processing of biofloc reduced its nutritional quality to Nile tilapia, which was in line with previous study that tilapia in the in-situ biofloc system grown better than dietary supplementation of biofloc [34]. The micronutrients (e.g. vitamins and free amino acids) or bioactive compounds (e.g. enzymes and carotenoids) in biofloc could be degraded or oxidized differently because of the heat, grinding, air or light submitted during the processing [11]. In our processing, the collection of biofloc from a swirl separator followed by filtration over a paper and subsequent dewatering, may result in the loss of active ingredients or bacteria in the in-situ biofloc that can enhance tilapia growth as observed in the LW treatment. 
Therefore, the growth-promoting effect of in-situ biofloc on Nile tilapia was confirmed in this study, while processing and dietary supplementation of biofloc may reduce its nutritional quality.

\section{LW Changed the Gut Microbiota Diversity and Distribution}

In addition to the growth-promoting effect of in-situ biofloc, some potential probiotic effects of biofloc were reported on cultured animals, such as modulation on gut microbiota, inhibition of pathogenic microorganisms and improvement of immune response [15, 24, 35]. Many studies have demonstrated the in-situ biofloc were associated with the shift of gut microbiota of shrimp [36-40]. However, studies on the effect of in-situ biofloc and dietary supplementation of ex-situ biofloc on the gut microbiota of tilapia are still rare. LW significantly increased the microbial diversity and richness in the gut of tilapia when compared with Ctrl (Fig. 2). Higher Shannon index and Chao 1 index were also observed in the gut of Litopenaeus vannamei reared in biofloc system than in the clear water system [41]. The introduction of live bacteria from biofloc to fish through water contact or flocs ingestion could act as bacterial source for colonization and thus increase the bacterial diversity and richness in the gut $[19,42]$. Improvement in microbial diversity is not always beneficial to the host, however, from the ecological point of view, higher taxonomic diversity is associated with higher functional redundancy and higher stability of the gut microbiota [43]. A more diverse gut microbiota was assumed to be beneficial to the fish, since higher growth performance and lower individual variations of the LW fish were observed in this study. The difference in gut microbial diversity between LW and Ctrl was attributed mostly to unrelated taxa on $\mathrm{d} 26$ since different PD whole tree index was observed [44]. On $\mathrm{d} 46$, the difference in microbial diversity between LW and Ctrl was caused by phylogenetically related taxa since the difference in PD whole tree index disappeared. In contrast, no significant differences were observed between DF vs Ctrl and LF vs Ctrl in the fish gut microbiota diversity, which implied that dietary supplementation of live or dead biofloc cannot mimic the microbial composition in the in-situ biofloc.

Furthermore, tilapia cultured in the in-situ biofloc (LW) exhibited a distinct gut microbiota composition when compared with other treatments while dietary supplementation of ex-situ biofloc (DF and LF) had similar gut microbiota composition as the Ctrl (Fig. 3). The gut microbiota development is thought relating with the changes of gut structure and functionality and the variations in water and feed microbial communities [23, 25, 45]. Temporal change in the fish gut microbiota composition was commonly observed in aquaculture [46, 47]. The temporal changes in the gut microbiota might be associated with the fact that the prokaryotic community in the rearing water (Fig. 5a), biofloc and feed (Fig. 5b) shifted over time. According to Giatsis et al. [25], the water samples collected from different tanks in one RAS had no difference in bacterial community. This explained that the Ctrl, DF and LF treatments had similar microbial community in the tank water from the same sampling timepoint (Table S5). However, due to the continuous influent from biofloc production system to the LW tanks, LW showed difference in water microbial community composition with other treatments. Moreover, the prokaryotic community in the feed for DF and LF were always different from the live biofloc (Fig. 5), implying that processing of biofloc changed the microbial composition in the in-situ biofloc. Therefore, the observed differences in the gut microbiota of tilapia in LW are associated with the unique microbial community created in both the in-situ flocs and the rearing water. However, this modulatory effect on gut microbiota was not observed through dietary supplementation of biofloc which might change the microbial composition in the processing of biofloc.

\section{Taxa Associated with the LW Treatment}

According to a standard procedure, the unique OTUs detected only in one sample was excluded from analysis [48]. With the temporal changes in fish gut microbiota development, four core genera showed more than $95 \%$ prevalence in all the gut samples (Fig. 4). Species belong to Cetobacterium and Peptostreptococcaceae were widely detected in the gut of Nile tilapia with high abundance [9, 18, 49-52]. The dietary treatment of in-situ or ex-situ biofloc changed the relative abundance of core gut microbiota of tilapia (Table 2). Examining the relative abundance of genera showed that LW changed the core taxa when compared with Ctrl treatment (Table 3). The relative abundance of Cetobacterium in fish gut was lower in LW (RA $=12.8 \%$ on $\mathrm{d} 26,32.7 \%$ on d49) than the Ctrl (RA $=43.9 \%$ on $\mathrm{d} 26,60.9 \%$ on $\mathrm{d} 49)$. This could be explained by the high abundance of Cetobacterium in the water from the $\mathrm{Ctrl}(\mathrm{RA}=24.2 \%), \mathrm{DF}(\mathrm{RA}=25.6 \%)$ and LF (RA $=23.6 \%)$, while only $6.0 \%$ was detected in the LW water. The effect of LW on the relative abundance of Peptostreptococcaceae was less clear, since Peptostreptococcaceae was lower on $\mathrm{d} 26$, but higher on $\mathrm{d} 49$ than the Ctrl. In contrast, Terrimicrobium showed a higher relative abundance in LW ( $\mathrm{RA}=26.8 \%$ on $\mathrm{d} 26,8.8 \%$ on $\mathrm{d} 49$ ) when compared with $\mathrm{Ctrl}(\mathrm{RA}=4.0 \%$ on $\mathrm{d} 26,0.5 \%$ on $\mathrm{d} 49)$. This could be explained by the relatively high abundance of Terrimicrobium in the biofloc and LW water (Fig. 5). Besides, those bacteria were detected with high prevalence and relative abundance in bioflocs, LW filtered water and LW fish gut (Fig. S4). In addition, 12 microbes present in bioflocs showed significantly higher relative abundance in the LW 
fish gut than the Ctrl fish gut (Fig. S4). This suggested that in-situ biofloc acts as a microbial source and modulates the gut microbiota assembly of fish cultured in the system, which might be potentially beneficial to the growth of Nile tilapia. To be noticed, Cetobacterium, Peptostreptococcaceae, and Terrimicrobium are all related with fermentative metabolism of peptides and carbohydrates [53-56]. Besides, Alsobacter and a genus belonging to the Fusobacteriales were identified as core taxa in LW but were absent in the Ctrl treatment. A species from Alsobacter isolated from soil samples could accumulate PHB granules [57]. The members of Fusobacteriales can ferment carbohydrates, amino acids and peptides to produce various short-chain fatty acids [58]. In summary, tilapia cultured in in-situ biofloc system (LW) showed a reduction in abundance of dominant Cetobacterium, meanwhile showed higher abundance of genera potentially involved in carbohydrate fermentation and short-chain fatty acids production. In contrast to dietary supplementation of biofloc, in-situ live biofloc changed the gut microbiota that may relate with feed digestion and in part explained the improved growth of fish in the LW treatment.

\section{Conclusions}

Nile tilapia exposed to in-situ biofloc (LW) had a consistently distinct gut microbiota by creating a different microbial community in the water column and the aggravation of biofloc. Rearing tilapia in LW increased the gut microbial diversity by reducing the relative abundance of dominant taxa and increasing the relative abundance of potentially beneficial bacteria. Nile tilapia grew better in LW than tilapia fed with processed live or dead biofloc and tilapia without biofloc. Dietary supplementation of live or dead biofloc at 5 and $10 \%$ weight base changed the original microbial composition of biofloc, which did not result in better growth nor influence the gut microbiota of tilapia.

Supplementary Information The online version contains supplementary material available at https://doi.org/10.1007/s00248-021-01880-y.

Acknowledgements We are grateful for the input from Hauke Smidt and Johan Verreth on the conceptualization of the experiment. We thank the staff of the aquaculture research facilities of Wageningen University, especially Menno ter Veld and Wian Nusselder, for their technical support in constructing the culture system and their help with fish dissection.

Author Contributions JVL, DS and MV contributed to study conception and design. Purpose build experiment tank design and set-up, as well as material preparation and animal husbandry was done by JVL. All authors contributed to sample processing, data collection and analyses. The first draft of the manuscript was started by KB and finalized by YD, upon which all authors commented and contributed to improving the manuscript, fine-tuning analyses and preparing the manuscript for submission. All authors read and approved the final manuscript.

Funding This research was financially supported by the NWO project (Bioflocs, the key to feed fish more with less, Grant No. 847.13.007). The author Yale Deng was financially supported by China Scholarship Council (Grant No. 201606320215).

Data Availability The datasets generated and analysed during the current study are available from the corresponding author on reasonable request.

Code Availability No special code was developed for data analysis in relation to this research.

\section{Declarations}

Conflict of Interest The authors declare they had no relevant financial or non-financial interests to disclose.

Ethical Approval All procedures involving animals were carried out under the registration code of AVD10400201544 which was approved by the Dutch Central Animal Experiments Committee and Animal Welfare Body of Wageningen University.

Consent of Participate Not applicable.

Consent for Publication Not applicable.

Open Access This article is licensed under a Creative Commons Attribution 4.0 International License, which permits use, sharing, adaptation, distribution and reproduction in any medium or format, as long as you give appropriate credit to the original author(s) and the source, provide a link to the Creative Commons licence, and indicate if changes were made. The images or other third party material in this article are included in the article's Creative Commons licence, unless indicated otherwise in a credit line to the material. If material is not included in the article's Creative Commons licence and your intended use is not permitted by statutory regulation or exceeds the permitted use, you will need to obtain permission directly from the copyright holder. To view a copy of this licence, visit http://creativecommons.org/licenses/by/4.0/.

\section{References}

1. De Schryver P, Crab R, Defoirdt T, Boon N, Verstraete W (2008) The basics of bio-flocs technology: the added value for aquaculture. Aquaculture 277:125-137. https://doi.org/10.1016/j.aquac ulture.2008.02.019

2. Avnimelech Y (2009) Biofloc technology: a practical guide book. World Aquaculture Society, Sorrento

3. Crab R, Defoirdt T, Bossier P, Verstraete W (2012) Biofloc technology in aquaculture: beneficial effects and future challenges. Aquaculture 356-357:351-356. https://doi.org/10.1016/j.aquac ulture.2012.04.046

4. Avnimelech Y (2007) Feeding with microbial flocs by tilapia in minimal discharge bio-flocs technology ponds. Aquaculture 264:140-147. https://doi.org/10.1016/j.aquaculture.2006.11.025

5. Azim ME, Little DC (2008) The biofloc technology (BFT) in indoor tanks: water quality, biofloc composition, and growth 
and welfare of Nile tilapia (Oreochromis niloticus). Aquaculture 283:29-35. https://doi.org/10.1016/j.aquaculture.2008.06.036

6. Long L, Yang J, Li Y, Guan C, Wu F (2015) Effect of biofloc technology on growth, digestive enzyme activity, hematology, and immune response of genetically improved farmed tilapia (Oreochromis niloticus). Aquaculture 448:135-141. https://doi.org/10. 1016/j.aquaculture.2015.05.017

7. Ekasari J, Rivandi DR, Firdausi AP, Surawidjaja EH, Zairin M, Bossier P, De Schryver P (2015) Biofloc technology positively affects Nile tilapia (Oreochromis niloticus) larvae performance. Aquaculture 441:72-77. https://doi.org/10.1016/j.aquaculture. 2015.02.019

8. Nevejan N, De Schryver P, Wille M, Dierckens K, Baruah K, Van Stappen G (2018) Bacteria as food in aquaculture: do they make a difference? Rev Aquacult 10:180-212. https://doi.org/10.1111/ raq. 12155

9. Liu G, Deng Y, Verdegem M, Ye Z, Zhu S (2019) Using poly(betahydroxybutyrate-beta-hydroxyvalerate) as carbon source in biofloc-systems: Nitrogen dynamics and shift of Oreochromis niloticus gut microbiota. Sci Total Environ 694:133664. https://doi.org/ 10.1016/j.scitotenv.2019.133664

10. Ekasari J, Crab R, Verstraete W (2010) Primary nutritional content of bio-flocs cultured with different organic carbon sources and salinity. HAYATI J Biosci 17:125-130. https://doi.org/10.4308/ hjb.17.3.125

11. Ju ZY, Forster I, Conquest L, Dominy W (2008) Enhanced growth effects on shrimp (Litopenaeus vannamei) from inclusion of whole shrimp floc or floc fractions to a formulated diet. Aquacult Nutr 14:533-543. https://doi.org/10.1111/j.1365-2095.2007.00559.x

12. Xu WJ, Pan LQ, Sun XH, Huang J (2013) Effects of bioflocs on water quality, and survival, growth and digestive enzyme activities of Litopenaeus vannamei (Boone) in zero-water exchange culture tanks. Aquacult Res 44:1093-1102. https://doi.org/10.1111/j. 1365-2109.2012.03115.x

13. Kuhn DD, Boardman GD, Lawrence AL, Marsh L, Flick GJ Jr (2009) Microbial floc meal as a replacement ingredient for fish meal and soybean protein in shrimp feed. Aquaculture 296:51-57

14. Kuhn DD, Lawrence AL, Boardman GD, Patnaik S, Marsh L, Flick GJ Jr (2010) Evaluation of two types of bioflocs derived from biological treatment of fish effluent as feed ingredients for Pacific white shrimp, Litopenaeus vannamei. Aquaculture 303:28-33

15. Ahmad I, Babitha Rani AM, Verma AK, Maqsood M (2017) Biofloc technology: an emerging avenue in aquatic animal healthcare and nutrition. Aquacult Int 25:1215-1226. https://doi.org/ 10.1007/s10499-016-0108-8

16. Qiao G, Chen P, Sun Q, Zhang M, Zhang J, Li Z, Li Q (2020) Poly- $\beta$-hydroxybutyrate (PHB) in bioflocs alters intestinal microbial community structure, immune-related gene expression and early Cyprinid herpesvirus 2 replication in gibel carp (Carassius auratus gibelio). Fish Shellfish Immunol 97:72-82. https://doi. org/10.1016/j.fsi.2019.12.045

17. Defoirdt T, Halet D, Vervaeren H, Boon N, Van de Wiele T, Sorgeloos P, Bossier P, Verstraete W (2007) The bacterial storage compound poly- $\beta$-hydroxybutyrate protects Artemia franciscana from pathogenic Vibrio campbellii. Environ Microbiol 9:445-452. https://doi.org/10.1111/j.1462-2920.2006.01161.x

18. Giatsis C, Sipkema D, Smidt H, Heilig H, Benvenuti G, Verreth J, Verdegem M (2015) The impact of rearing environment on the development of gut microbiota in tilapia larvae. Sci Rep 5:18206. https://doi.org/10.1038/srep18206

19. Li J, Liu G, Li C, Deng Y, Tadda MA, Lan L, Zhu S, Liu D (2018) Effects of different solid carbon sources on water quality, biofloc quality and gut microbiota of Nile tilapia (Oreochromis niloticus) larvae. Aquaculture. https://doi.org/10.1016/j.aquaculture.2018. 06.078
20. Pérez-Fuentes JA, Pérez-Rostro CI, Hernández-Vergara MP, Monroy-Dosta MdC (2018) Variation of the bacterial composition of biofloc and the intestine of Nile tilapia Oreochromis niloticus, cultivated using biofloc technology, supplied different feed rations. Aquacult Res 49:3658-3668. https://doi.org/10.1111/are.13834

21. de Bruijn I, Liu Y, Wiegertjes GF, Raaijmakers JM (2017) Exploring fish microbial communities to mitigate emerging diseases in aquaculture. FEMS Microbiol Ecol 94(1):161. https://doi.org/10. 1093/femsec/fix 161

22. Nayak SK (2010) Role of gastrointestinal microbiota in fish. Aquacult Res 41:1553-1573. https://doi.org/10.1111/j.1365-2109. 2010.02546.x

23. Vadstein O, Bergh O, Gatesoupe FJ, Galindo-Villegas J, Mulero V, Picchietti S, Scapigliati G, Makridis P, Olsen Y, Dierckens K, Defoirdt T, Boon N, De Schryver P, Bossier P (2013) Microbiology and immunology of fish larvae. Rev Aquacult 5:S1-S25. https://doi.org/10.1111/j.1753-5131.2012.01082.x

24. Verschuere L, Rombaut G, Sorgeloos P, Verstraete W (2000) Probiotic bacteria as biological control agents in aquaculture. Microbiol Mol Biol R 64:655. https://doi.org/10.1128/Mmbr.64.4.655671.2000

25. Giatsis C, Sipkema D, Smidt H, Verreth J, Verdegem M (2014) The colonization dynamics of the gut microbiota in tilapia larvae. PLoS ONE 9:e103641. https://doi.org/10.1371/journal. pone. 0103641

26. Gu F, Borewicz K, Richter B, van der Zaal PH, Smidt H, Buwalda PL, Schols HA (2018) In vitro fermentation behavior of isomalto/malto-polysaccharides using human fecal inoculum indicates prebiotic potential. Mol Nutr Food Res 62:e1800232. https://doi.org/10.1002/mnfr.201800232

27. Ramiro-Garcia J, Hermes GDA, Giatsis C, Sipkema D, Zoetendal EG, Schaap PJ, Smidt H (2016) NG-Tax, a highly accurate and validated pipeline for analysis of $16 \mathrm{~S}$ rRNA amplicons from complex biomes. F1000Research 5:1791. https://doi.org/ 10.12688/f1000research.9227.1

28. Quast C, Pruesse E, Yilmaz P, Gerken J, Schweer T, Yarza P, Peplies J, Glockner FO (2013) The SILVA ribosomal RNA gene database project: improved data processing and web-based tools. Nucleic Acids Res 41:D590-596. https://doi.org/10.1093/ nar/gks 1219

29. Saravanan S, Geurden I, Figueiredo-Silva AC, Kaushik SJ, Haidar MN, Verreth JA, Schrama JW (2012) Control of voluntary feed intake in fish: a role for dietary oxygen demand in Nile tilapia (Oreochromis niloticus) fed diets with different macronutrient profiles. Br J Nutr 108:1519-1529. https://doi. org/10.1017/S0007114511006842

30. Kuczynski J, Stombaugh J, Walters WA, González A, Caporaso JG, Knight R (2012) Using QIIME to analyze 16S rRNA gene sequences from microbial communities. Curr Protoc Microbiol 27:1E.5.1-1E.5.20

31. Šmilauer P, Lepš J (2014) Multivariate analysis of ecological data using CANOCO 5. Cambridge University Press, Cambridge

32. Luo G, Gao Q, Wang C, Liu W, Sun D, Li L, Tan H (2014) Growth, digestive activity, welfare, and partial cost-effectiveness of genetically improved farmed tilapia (Oreochromis niloticus) cultured in a recirculating aquaculture system and an indoor biofloc system. Aquaculture 422-423:1-7. https://doi.org/10.1016/j. aquaculture.2013.11.023

33. Hisano H, Barbosa PTL, Hayd LA, Mattioli CC (2019) Evaluation of Nile tilapia in monoculture and polyculture with giant freshwater prawn in biofloc technology system and in recirculation aquaculture system. Int Aquat Res 11:335-346. https://doi.org/10. 1007/s40071-019-00242-2

34. Menaga M, Felix S, Charulatha M, Gopalakannan A, Panigrahi A (2019) Effect of in-situ and ex-situ biofloc on immune response 
of genetically improved farmed Tilapia. Fish Shellfish Immunol. https://doi.org/10.1016/j.fsi.2019.06.031

35. Ferreira GS, Bolívar NC, Pereira SA, Guertler C, Vieira FdN, Mouriño JLP, Seiffert WQ (2015) Microbial biofloc as source of probiotic bacteria for the culture of Litopenaeus vannamei. Aquaculture 448:273-279. https://doi.org/10.1016/j.aquaculture. 2015.06.006

36. Huang L, Guo H, Chen C, Huang X, Chen W, Bao F, Liu W, Wang S, Zhang D (2020) The bacteria from large-sized bioflocs are more associated with the shrimp gut microbiota in culture system. Aquaculture 523:735159. https://doi.org/10.1016/j.aquac ulture.2020.735159

37. Tepaamorndech S, Nookaew I, Higdon SM, Santiyanont P, Phromson M, Chantarasakha K, Mhuantong W, Plengvidhya V, Visessanguan W (2020) Metagenomics in bioflocs and their effects on gut microbiome and immune responses in Pacific white shrimp. Fish Shellfish Immunol 106:733-741. https://doi.org/10. 1016/j.fsi.2020.08.042

38. de Souza VC, Rodiles A, Freire Marques MR, Merrifield DL (2020) White spot syndrome virus (WSSV) disturbs the intestinal microbiota of shrimp (Penaeus vannamei) reared in biofloc and clear seawater. Appl Microbiol Biot 104:8007-8023. https://doi. org/10.1007/s00253-020-10816-4

39. Panigrahi A, Esakkiraj P, Jayashree S, Saranya C, Das RR, Sundaram M (2019) Colonization of enzymatic bacterial flora in biofloc grown shrimp Penaeus vannamei and evaluation of their beneficial effect. Aquacult Int 27:1835-1846. https://doi.org/10.1007/ s10499-019-00434-X

40. Deng Y, Xu X, Yin X, Lu H, Chen G, Yu J, Ruan Y (2019) Effect of stock density on the microbial community in biofloc water and Pacific white shrimp (Litopenaeus vannamei) gut microbiota. Appl Microbiol Biotechnol. https://doi.org/10.1007/ s00253-019-09773-4

41. Pilotto MR, Goncalves ANA, Vieira FN, Seifert WQ, Bachere E, Rosa RD, Perazzolo LM (2018) Exploring the impact of the biofloc rearing system and an oral WSSV challenge on the intestinal bacteriome of Litopenaeus vannamei. Microorganisms. https:// doi.org/10.3390/microorganisms6030083

42. Cardona E, Gueguen Y, Magré K, Lorgeoux B, Piquemal D, Pierrat F, Noguier F, Saulnier D (2016) Bacterial community characterization of water and intestine of the shrimp Litopenaeus stylirostris in a biofloc system. BMC Microbiol 16:157. https:// doi.org/10.1186/s12866-016-0770-Z

43. Moya A, Ferrer M (2016) Functional redundancy-induced stability of gut microbiota subjected to disturbance. Trends Microbiol 24:402-413. https://doi.org/10.1016/j.tim.2016.02.002

44. Faith DP, Baker AM (2006) Phylogenetic diversity (PD) and biodiversity conservation: some bioinformatics challenges. Evol Bioinform 2:117693430600200000. https://doi.org/10.1177/11769 3430600200007

45. Stephens WZ, Burns AR, Stagaman K, Wong S, Rawls JF, Guillemin K, Bohannan BJ (2016) The composition of the zebrafish intestinal microbial community varies across development. Isme J 10:644-654. https://doi.org/10.1038/ismej.2015.140

46. Bledsoe JW, Peterson BC, Swanson KS, Small BC (2016) Ontogenetic characterization of the intestinal microbiota of channel catfish through 16S rRNA gene sequencing reveals insights on temporal shifts and the influence of environmental microbes. PLoS ONE 11:e0166379. https://doi.org/10.1371/journal.pone.0166379
47. Keating C, Bolton-Warberg M, Hinchcliffe J, Davies R, Whelan S, Wan AHL, Fitzgerald RD, Davies SJ, Ijaz UZ, Smith CJ (2021) Temporal changes in the gut microbiota in farmed Atlantic cod (Gadus morhua) outweigh the response to diet supplementation with macroalgae. Animal Microbiome 3:7. https://doi.org/10. 1186/s42523-020-00065-1

48. Deng Y, Verdegem MC, Eding E, Kokou F (2021) Effect of rearing systems and dietary probiotic supplementation on the growth and gut microbiota of Nile tilapia (Oreochromis niloticus) larvae. Aquaculture 6:737297. https://doi.org/10.1016/j.aquaculture. 2021.737297

49. Adeoye AA, Yomla R, Jaramillo-Torres A, Rodiles A, Merrifield DL, Davies SJ (2016) Combined effects of exogenous enzymes and probiotic on Nile tilapia (Oreochromis niloticus) growth, intestinal morphology and microbiome. Aquaculture 463:61-70. https://doi.org/10.1016/j.aquaculture.2016.05.028

50. Melo-Bolívar JF, Ruiz Pardo RY, Hume ME, Nisbet DJ, Rodríguez-Villamizar F, Alzate JF, Junca H, Villamil Díaz LM (2019) Establishment and characterization of a competitive exclusion bacterial culture derived from Nile tilapia (Oreochromis niloticus) gut microbiomes showing antibacterial activity against pathogenic Streptococcus agalactiae. PLoS ONE 14:e0215375. https://doi. org/10.1371/journal.pone.0215375

51. Ran C, Huang L, Hu J, Tacon P, He S, Li Z, Wang Y, Liu Z, Xu L, Yang Y, Zhou Z (2016) Effects of dietary live and heatinactive baker's yeast on growth, gut health, and disease resistance of Nile tilapia under high rearing density. Fish Shellfish Immunol 56:263-271. https://doi.org/10.1016/j.fsi.2016.07.001

52. Maas RM, Deng Y, Dersjant-Li Y, Petit J, Verdegem MCJ, Schrama JW, Kokou F (2021) Exogenous enzymes and probiotics alter digestion kinetics, volatile fatty acid content and microbial interactions in the gut of Nile tilapia. Sci Rep 11:8221. https://doi. org/10.1038/s41598-021-87408-3

53. Finegold SM, Vaisanen M-L, Molitoris DR, Tomzynski TJ, Song Y, Liu C, Collins MD, Lawson PA (2003) Cetobacterium somerae sp. nov. from human feces and emended description of the genus Cetobacterium. Syst Appl Microbiol 26:177-181. https://doi.org/ 10.1078/072320203322346010

54. Slobodkin A (2014) The Family Peptostreptococcaceae. The Prokaryotes. Firmicutes and Tenericutes, pp 291-302

55. Cabello-Yeves PJ, Ghai R, Mehrshad M, Picazo A, Camacho A, Rodriguez-Valera F (2017) Reconstruction of diverse verrucomicrobial genomes from metagenome datasets of freshwater reservoirs. Front Microbiol. https://doi.org/10.3389/fmicb.2017.02131

56. Qiu Y-L, Kuang X-z, Shi X-s, Yuan X-z, Guo R-b (2014) Terrimicrobium sacchariphilum gen. nov., sp. nov., an anaerobic bacterium of the class 'Spartobacteria' in the phylum Verrucomicrobia, isolated from a rice paddy field. Int J Syst Evol Micr 64:1718-1723

57. Bao Z, Sato Y, Fujimura R, Ohta H (2014) Alsobacter metallidurans gen. nov., sp. nov., a thallium-tolerant soil bacterium in the order Rhizobiales. Int J Syst Evol Micr 64:775-780. https:// doi.org/10.1099/ijs.0.054783-0

58. Olsen I (2014) The family fusobacteriaceae. The prokaryotes: Firmicutes and Tenericutes. pp 109-132 